Mémoire de Maîtrise en médecine No 4348

\title{
Hospital disaster preparedness in Switzerland over a decade: a national survey
}

\author{
Etudiant \\ Dell'Era Simone \\ Tuteur \\ Hügli Olivier William \\ Service des Urgences \\ Co-tuteur \\ Dami Thierry \\ Service des Urgences

\section{Expert} \\ Rutschmann Olivier \\ Service des Urgences HUG
}

Lausanne, 13.12.2017 


\section{Swiss Medical Weekly \\ Hospital disaster preparedness in Switzerland over a decade: a national survey --Manuscript Draft--}

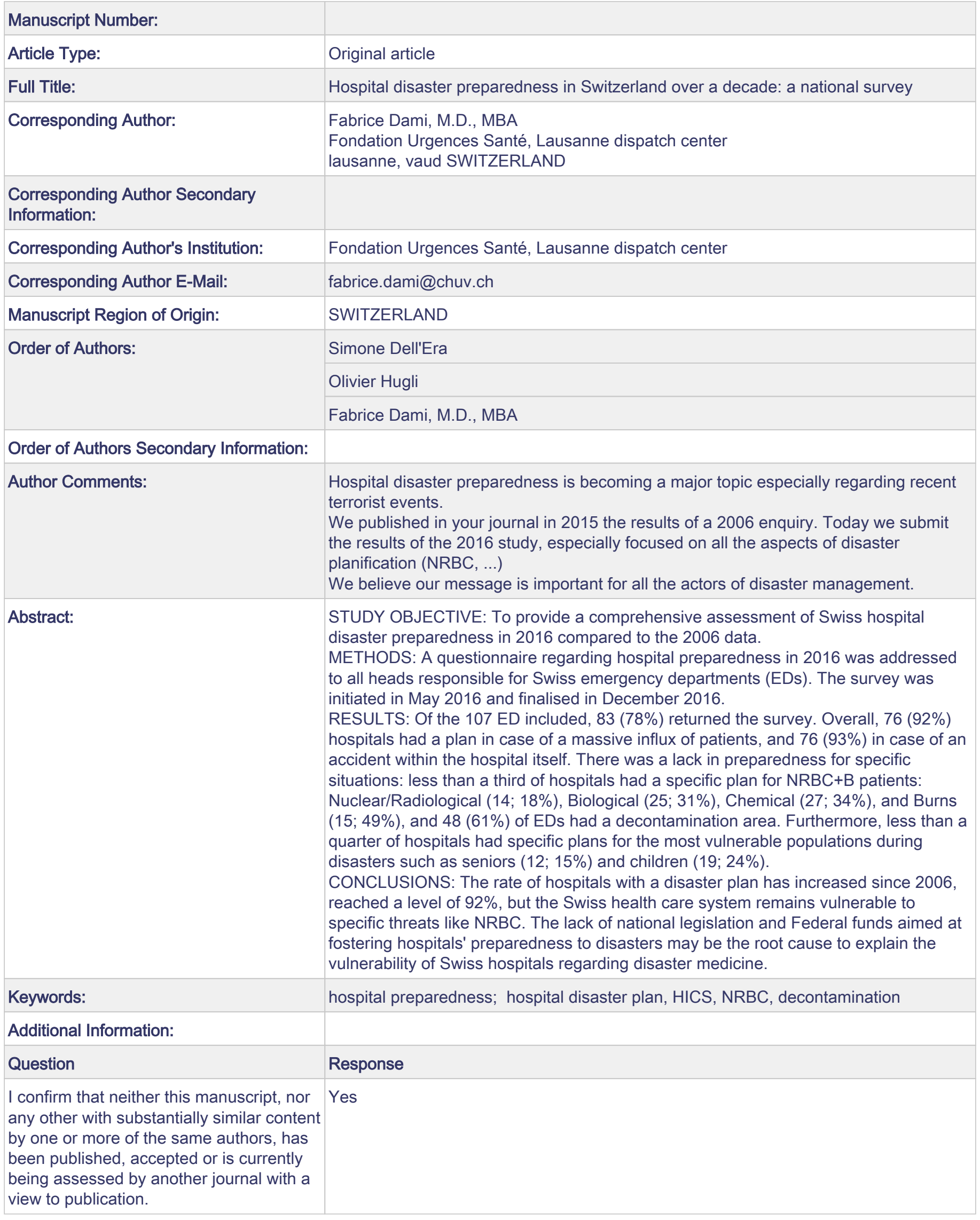


I certify that all authors have participated sufficiently (1) in the conception and design, or acquisition of data, or analysis and interpretation of data; (2) drafting the article or revising it critically for important intellectual content; and (3) final approval of the version to be published.

Trial registration number: We encourage the registration of clinical trials in a primary registry that participates in WHO's International Clinical Trial Registry

Platform. The ICMJE defines a clinical trial as any research project that prospectively assigns human subjects to intervention or concurrent comparison or control groups to study the cause-andeffect relationship between a medical intervention and a health outcome. Medical interventions include drugs, surgical procedures, devices, behavioral treatments, process-of-care changes, and the like. Please include the trial registration number and the name of the trial registry at the end of the abstract too.

We require every article reporting results of prospective research using human subjects or samples or results of animal research to include a statement that the study obtained ethics approval, including the name of the ethics committee(s) or institutional review board(s) and the number/ID of the approval(s). Where ethical approval is not required, the manuscript should include a clear statement of this and the reason why.

Please specify the study design. Please note that particular forms of articles submitted to SMW should adhere to reporting guidelines as specified below:

Have you obtained consent from the patient if there is an unavoidable risk of breach of privacy? (Please note that the manuscript will not be reviewed until this consent is received.)

Have figures or tables from other publications been used? (Permission to reprint figures or tables from other publications must be obtained by the author prior to submission of the manuscript. A copy of the permission from the copyright holder has to be sent to the editorial office.)

Please disclose outside financial support or other financial relationships (both personal and institutional) that could be viewed as presenting a potential conflict of interest in connection with the submitted manuscript. A conflict of interest statement is published with each paper.

(We do not need to receive signed copies
Yes

0

s

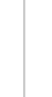

Name of the ethics committee(s) or institutional review board(s):The Human Research Ethics Committee of the State of Vaud

Number/ID of the approval(s): no formular was required from the committe for this study

\title{
Other
}

\author{
No - - Informed consent is not necessary for this paper.
}

No - No copyrighted material has been used.

none 
of the authors' forms now, but if your manuscript is accepted for publication the editorial office will ask you to return the authors' forms signed by each author.)

Do you apply for rapid publication? (If you no feel that for reasons of general or public interest your manuscript requires more expeditious publication and quick processing through peer review, you may inform the Editorial Board indicating: the reasons the authors think the manuscript should be published immediately and the implications of the findings.)

Suggested Reviewers: 


\section{Hospital disaster preparedness in Switzerland over a decade: a national survey}

Simone Dell'Era ${ }^{1}$, Olivier Hugli², Fabrice Dami ${ }^{2}$

1) Medical school, University of Lausanne, Lausanne, Switzerland

2) Emergency Department, University Hospital of Lausanne (CHUV), Lausanne, Switzerland

Simone Dell'Era, Master student, Faculty of Medicine, Lausanne University, Lausanne, Switzerland

Olivier Hugli, MD, MPH, Emergency Department, University Hospital of Lausanne (CHUV), Lausanne, Switzerland

Fabrice Dami, MD, MBA, Emergency Department, University Hospital of Lausanne (CHUV), Lausanne, Switzerland

Keywords: hospital preparedness; hospital disaster plan, HICS, NRBC, decontamination.

Corresponding author:

Fabrice Dami, MD, MBA

Emergency Department of Lausanne University Hospital

Bugnon $46^{*}$

1011 Lausanne, Switzerland

Email: fabrice.dami@chuv.ch 


\begin{abstract}
STUDY OBJECTIVE: To provide a comprehensive assessment of Swiss hospital disaster preparedness in 2016 compared to the 2006 data.

METHODS: A questionnaire regarding hospital preparedness in 2016 was addressed to all heads responsible for Swiss emergency departments (EDs). The survey was initiated in May 2016 and finalised in December 2016.
\end{abstract}

RESULTS: Of the 107 ED included, 83 (78\%) returned the survey. Overall, 76 (92\%) hospitals had a plan in case of a massive influx of patients, and $76(93 \%)$ in case of an accident within the hospital itself. There was a lack in preparedness for specific situations: less than a third of hospitals had a specific plan for NRBC+B patients: Nuclear/Radiological (14; 18\%), Biological (25; $31 \%)$, Chemical $(27 ; 34 \%)$, and Burns $(15 ; 49 \%)$, and $48(61 \%)$ of EDs had a decontamination area. Furthermore, less than a quarter of hospitals had specific plans for the most vulnerable populations during disasters such as seniors (12; 15\%) and children (19; 24\%).

CONCLUSIONS: The rate of hospitals with a disaster plan has increased since 2006, reached a level of $92 \%$, but the Swiss health care system remains vulnerable to specific threats like NRBC. The lack of national legislation and Federal funds aimed at fostering hospitals' preparedness to disasters may be the root cause to explain the vulnerability of Swiss hospitals regarding disaster medicine. 


\section{Introduction}

At the beginning of the sixteenth century, Nicolas Machiavelli in his political treatise "The Prince" maintained that during a storm, the overflowing impetuous river could destroy everything in its path, and that a good governor was one who built banks in calmer times (1).

Following a natural or man-made disaster, patients present to local hospitals, whose EDs are often chronically overcrowded (2). Additionally, the hospital itself can be damaged by the disaster or itself suffer a major incident like fire, power and telecommunication breakdown $(3,4)$. The two key determinants required to minimise the impact of those events are the existence of a disaster plan and regular training through simulation exercises $(5,6)$, as demonstrated recently during the bombing of the Boston Marathon (2013) or the Paris attacks in 2015 (5,7). Since the terrorist attacks on September 11 2001 in New York, drills have become part of the National Bioterrorism Hospital Preparedness Plan in the USA (8), and the Federal state incites simulation development and provides financial support and coordination $(9,10)$.

Switzerland is a federation of 26 States. As in the USA or in Germany (11), the health care system is fragmented and highly decentralised. Each state is sovereign to rule on hospital disaster preparedness legislation (12). There is no national legally binding medical standard (13), except for pandemic crises (14), infectious diseases such as HIV/AIDS, vaccines (12) and nuclear incidents (15). Switzerland is among the richest countries in the world (12) and has a system of public health surpassed only by the USA in per capita costs (16). However, disaster preparedness is costly to achieve and maintain for hospitals, with costs ranging from one to more than three million dollars per hospital in the USA $(9,17)$. Furthermore, forprofit privately funded hospitals are more exposed to competition in the hospital or insurance markets than public institutions (12), and some data suggest their level of preparedness may be less efficient (18). 
In 2006 , only $82 \%$ of Swiss hospitals had a disaster plan following an national survey (19). Many

hospitals have since updated their disaster plan, in particular since Switzerland co-hosted the Eurofoot in 2008. Unlike in the USA, there is however neither financial support nor coordination to organise drills on a national level within Switzerland.

The main objective of this study was to compare the proportion of hospitals with a disaster plan in 2016 with the proportion in 2006. Secondary objectives were to assess the type of risks hospitals were prepared for, and their declared level of preparedness.

\section{Materials and Methods}

As no validated questionnaire exists in the literature, a specific questionnaire was prepared for this survey, based on the main criteria of hospital disaster preparedness identified in a review of the literature. Queries from the 2006 survey were included to allow for comparisons with our initial survey. An email invitation to participate was sent to all heads of EDs if the ED was hospital-based and open on a $24 / 7$ basis. The list of participating hospitals from the last survey was updated with data from the Federal Office of Public Health. Hospital-based EDs admitting adult as well as paediatric patients were included. Specialty EDs dedicated only to ophthalmology or psychiatry were excluded on account of their highly specialised structures and technical capabilities. In the case of multi-site hospital EDs, the Head of the ED decided either to consider the hospital as a single hospital or as several hospitals. Paediatric ED plans were considered only if different from the adult ED.

The survey was conducted using the online platform SurveyMonkey®. If no answer was received, a letter containing the questionnaire in paper format was sent. Data collection was conducted from May to December 2016.

The Human Research Ethics Committee of the State of Vaud, Switzerland was consulted; however, as no data from patients were processed, no further documentation was required. 


\section{$\underline{\text { Statistical analysis }}$}

Statistical analyses were performed using Stata 14.1 (StataCorp, College Station, TX, USA). Data are presented as mean \pm standard deviation (SD), median and inter-quartile range (IQR) or as percentages. Proportions were compared using the Chi-squared test, or Fisher's exact test, and means using unpaired Student's t-test or Wilcoxon rank sum test, as appropriate. A bilateral P value $<0.05$ was considered statistically significant. Missing data were not imputed.

\section{Results}

In 2016, there were 107 hospitals (138 in 2006) open 24/7, which equates to 26 hospitals/10,000 $\mathrm{km}^{2}$. Of those, $83(78 \%)$ hospitals completed the questionnaire, with a rate that was similar to the $78 \%$ reported in the 2006 study. In 2006, 89 (82\%) hospitals had a disaster plan in case of the massive influx of patients; this increased to $92 \%$ in $2016(\mathrm{P}=0.088)$. Public hospitals more frequently had a disaster plan than private ones in $2006(P=0.017)$, and, although a difference still existed in 2016 (94\% for public hospital vs. 80\% for private ones), it was no longer statistically significant $(P=0.107)$. The number of hospital beds was not associated with the existence of a disaster plan in both study periods. In 2006, there were no statistically significant differences in the percentage of disaster plans between the three main linguistic parts of the country. In 2016, however, we noticed that the French part of Switzerland had a significantly lower proportion of hospitals with disaster plans $(p=0.040)$. As in 2006 , all university hospitals that responded had a plan in 2016 (Table 1).

\section{Disaster plan features in 2016 (Table 2)}

Most hospitals had a plan in case of the massive influx of patients or in the case of an accident within the hospital itself $(76 ; 92 \%)$. Plans regarding casualties of specific types of disasters were present in the following proportions: Polytrauma $(n=46 ; 58 \%)$, Chemical $(n=27 ; 34 \%)$, Biological $(n=25 ; 31 \%)$, Nuclear/Radiologic $(n=14 ; 18 \%)$ and Burns $(n=15 ; 19 \%)$. Plans addressing the needs of specific types of patients existed in a minority of hospitals: children ( $n=19 ; 24 \%)$, elderly ( $n=12$; $15 \%)$; and migrants $(n=10 ; 13 \%)$. 
The control of hospital ED access was performed in 34 (43\%) hospitals by its own technical staff, by private security services in $29(36 \%)$, and by police forces in $24(30 \%)$. Most hospitals $(n=41$; $51 \%)$ planned to separate the flow of daily patients from that of the disaster. Regarding the patient flow management, 67 (81\%) hospitals used digital support on a daily basis, whereas 52 (67\%) would still use such support during a disaster situation. In 79 (98\%) hospitals, the plan anticipated the potential recall of additional staff; in 74 hospitals (93\%) the recalled staff were from the ED, while in $71(89 \%)$ hospitals, staff from other departments were likely to be recalled. Finally, 64 (80\%) hospitals could also recall administrative staff.

\section{Plan knowledge, learning and drills}

In most cases, the medical staff were informed about the plan through periodic instruction $(n=50$; $64 \%)$ or by consulting the hospital website $(n=49 ; 63 \%)$. Word-of-mouth $(n=15 ; 19 \%)$ and pocket card $(n=11 ; 14 \%)$ were also reported means of communication. Half of the hospitals $(n=42 ; 52 \%)$ performed at least one simulation drill per year, while all hospitals organised at least one exercise per 3-year period. The most frequently used drill mode was activation of the Hospital Incident Command System (HICS) alone ( $n=38 ; 48 \%)$. The use of simulated patients $(n=33 ; 41 \%)$ and cards ( $n=27 ; 34 \%)$ was less frequent (Table 2$)$.

Figure 1 displays the degree of awareness of the plan from the staff according to the Heads of Emergency Departments. It appears that just over half of ED department heads (42; 54\%) and nurses $(44 ; 56 \%)$ knew the plan at least sufficiently. For interns, however, the proportion of adequate knowledge was lower (14; 18\%).

\section{Hospital incident Command System (HICS) (Table 2)}

Most hospitals ( $n=70 ; 88 \%$ ) had a HICS, the leader of which was a member of the hospital management $(n=38 ; 56 \%)$ or the medical officer of the ED $(14 ; 21 \%)$ in most cases. The majority ( $n=38 ; 56 \%$ ) estimated the time necessary for the HICS to be operational to be 20 to 40 minutes. 


\section{Decontamination (Table 2)}

Sixty percent of hospitals $(n=47)$ had a decontamination zone for a chemical accident, $32(41 \%)$ had one for a biological accident, 25 (32\%) for a nuclear one, and 30 (39\%) had no decontamination zone. The decontamination area was operational within $40 \pm 25$ minutes on average, with a median time of 30 minutes (IQR 60-20). The medical staff were responsible for decontamination in 26 (54\%) hospitals, the hospital technical staff in $23(48 \%)$, and fire-fighters in 19 (40\%). Among hospitals equipped with a decontamination zone, 44 (92\%) reported having protective masks with disposable gloves, and 38 (79\%) reported providing lightweight chemical protection (PPE).

\section{Plan development}

Most of hospitals (46; 58\%) had developed their plan through States' coordination, and 29 (36\%) with other hospitals in their region (Annexe 1). Rescue agencies were also involved in the development of the disaster plan: Emergency medical services in 43 (54\%) situations, fire-fighters in $33(41 \%)$, and the police in $23(29 \%)$. The Federal state and its entities (Army, Federal Office for the Protection of Population) cooperated in less than $10 \%$ of disaster plan developments. In half of the cases $(39 ; 49 \%)$, the Federal state required hospitals to develop a disaster plan but more frequently, the disaster plan development resulted from the initiative of a sole executive of the hospital $(n=30 ; 38 \%)$ or due to preparation for an important event in the region $(19 ; 24 \%)$. (Annexe 2).

\section{Discussion}

This study is the first to provide a comprehensive analysis of the evolution of the disaster and inhospital event preparedness of Swiss hospitals.

We noticed a decrease in the total number of disaster plans in 2016 . This can be explained by the decrease in the number of eligible hospitals; in 2016, multi-site hospital EDs with the same disaster plan were often counted as one. This phenomenon mainly affected the French region, which may explain the absolute reduction of disaster plans in this part of the country. 
However, compared to 2006 , the proportion of hospitals with a disaster plan in case of massive patient inflow in 2016 had increased to 92\%. In 2012, in a similar survey covering the European Union, a rate of $82 \%$ covering the same risk was reported (20).

All university hospitals have a plan; the size of the hospital does not seem to affect the presence of a plan.

The 2015 Swiss Federal Office for the Protection of Population report approximates that severe chemical or biological accidents may occur more than once in 100 years, nuclear accidents once in 30,000 years and that international events of a social nature (e.g. terrorist attacks with NRBC) are impossible to estimate (21). When these disasters occur, decontamination is indispensable to prevent the spread of toxic agents in the hospital, thereby contaminating both patients and staff (22). In this research, only half of hospitals had a decontamination area, only a third had a specific plan for NRBC+B patients and another third had no decontamination area at all. This is a major weakness, as decontamination is not always done at the site of the accident. Furthermore, walking-wounded patients often bypass on-site treatment and decontamination stations to go directly to the nearest hospitals (23). In a similar study conducted in 2012 in Europe, 70\% of hospitals had a specific plan dedicated to chemical incidents (20), while in another study conducted in 2008 in the USA, $67 \%$ of hospitals from the sample had response plans for all six categories of expected incidents (24).

Most hospitals believed that the decontamination area should be handled by care staff or by firefighters, but healthcare providers may not be properly trained and already busy in other tasks, with fire-fighters deployed at the accident site (10). Another issue is the time needed to setup an operational decontamination area (30-40 minutes), while the first patients may arrive in the emergency department (ED) within 5-30 minutes (25). Contaminated patients could contaminate equipment and the ED staff if they are not adequately protected. Our results in $\mathrm{NRBC}+\mathrm{B}$ disaster preparedness are therefore worrying. As noted by Noto (1994), despite the fact that pure NRBC+B incidents are rare, a disaster can include NRBC+B components with related casualties; therefore, NRBC+B victims are more frequent than expected (26). However, this survey shows that basic personal protective equipment, such as PPE and protective masks, are available in most hospitals, 
in a proportion similar to a recent survey of chemical hazard preparedness in hospitals in Michigan, USA (27), and as proposed by Koenig et al. (22).

Disaster plans specifically designed for particular populations of patients (elderly, children, migrants) have already proven their benefits $(28,29)$. However, most Swiss hospitals do not have such plans. As a fifth of the population is over 65 years with a projection of more than a quarter in 2030 (30), an awareness of the lack of a dedicated plan is a first step towards preparing better Swiss hospitals ourselves. Similarly, children are often involved in disasters, and their health needs may be specific. MD George Foltin recommended that children should be given primary transport to paediatric centres, but, if this is not possible, general hospitals which normally deal with adults should have plans in place to adequately take care of children (31). Paediatric exercises, equipment and expertise are therefore essential in every hospital (31).

In case of disasters, the presence of a care team for patients' families is essential (26). This enables the ED to focus on patient care exclusively. Most hospitals report not having such resources, while half consider the care of victims' relatives to be an ED task.

During a major disaster, it is often necessary to call for additional staff (32); most hospitals have such a plan. However, regarding the size of Switzerland and its borders, staff may live in another country, where borders may be closed for security reasons (terrorism, natural disaster). This eventuality must be considered.

\section{Knowledge of the disaster plan}

Interns seem to be the less prepared professional category. This may be explained by the short periods that interns experience in the ED in Switzerland; there is not enough time to participate to the drills, nor to learn the procedures when dealing with a major incident. A 2013 Germany survey showed similar results, with only $53 \%$ of physicians knowing that there is a plan in their hospital (33). 
Only half of hospitals perform at least one simulation per year while they all declare to go through

at least one exercise every 3-years. As suggested by many, the retention of knowledge regarding disaster plan rules is directly related to the time since the last training session (34). Additionally, $69 \%$ of hospitals that normally use digital support in a daily situation will use paper support in a disaster situation. More frequent exercises are therefore essential to accustom the staff to this important change. Unfortunately, the lack of tangible immediate benefits makes it difficult to justify those drills, especially when time, structures and money are limited (10). In addition, the chronic shortage of care staff makes the participation of key workers in simulations, rather than their use for daily management duty, difficult. On the other hand, poor management of a disaster can result in poor publicity for the hospital, a more serious psychological impact of the disaster on employees and patients, and even lead to the closure of the hospital (10). These factors therefore contribute to heterogeneity in the degree of disaster preparedness. One possible solution is the joint conception of disaster plans between hospitals (10). Interestingly, unlike the rest of Switzerland, all hospitals in the Italian speaking region have developed a plan through regional coordination. This probably explains the widespread uniformity of responses among hospitals of the Italian speaking region with a disaster plan rate that reaches $100 \%$.

According to Barbera et al. (2009), an additional factor that promotes hospital disaster preparedness is the presence of federal funding and guidance (10). The Swiss Federal Office for the Protection of Population supports the State's pre-hospital organisations (EMS, police, firefighters, Civil Protection, Army) to exercise their disasters plans (35). However, this support does not extend to hospitals that are under the State's responsibility only (12). Half of all hospitals declare that their State obliges them to develop a plan, while a minority even declare that they developed a plan because of Federal obligation. However, such obligation does not exist. Unlike in the USA, there is neither Federal nor State financial support for hospitals to organise drills in Switzerland. This lack of national coordination and funding induces a large heterogeneity in the degree of achievement of disaster plans and their testing within hospitals. 


\section{Limitations}

Only $78 \%$ of eligible hospitals participated to the survey; as there are no data from non-responding hospitals, we cannot assess whether their characteristics differed significantly. We have identified 53 determinants of disaster preparedness from a medical perspective based on the literature. However, we have not investigated other aspects of disaster preparedness such as administrative or logistics preparedness. The invitation to complete the questionnaire was sent to the heads of the Swiss emergency services. The answers obtained reflect their knowledge and not necessarily the reality of the plan.

\section{Conclusion}

The 2006-2016 analysis of Swiss hospital disaster preparedness shows improvements, with 92\% of hospitals declaring having a plan in the case of massive patient inflow. However, some specific situations are not covered, especially NRBC risks and paediatric victims. National guidelines, financial incentives, and simulations are still lacking.

\section{Statement on funding sources and conflicts of interest}

The authors declare no funding sources, neither conflict of interest.

\section{Acknowledgments}

We are thankful to all the ED heads who returned our questionnaire and for their insightful suggestions. We would like to thank Michele Dell'Era, for his helpful comments on the statistical analysis. 


\section{References}

1. Machiavelli Niccolò. The prince. 10th ed. Milan: Feltrinelli; 2013. 256 p.

2. Schneider SM, Gallery ME, Schafermeyer R, Zwemer FL. Emergency department crowding: a point in time. Ann Emerg Med. 2003 Aug;42(2):167-72.

3. Salamati Nia SP, Kulatunga U. The challenges of hospital disaster managers in natural disaster events. In Seville, Spain; 2017 [cited 2017 Sep 20]. Available from: http://usir.salford.ac.uk/42613/

4. Dami F, Carron P-N, Yersin B, Hugli O. University Hospital Struck Deaf and Silent by Lightning: Lessons to Learn. Disaster Med Public Health Prep. 2015 Aug;9(4):440-3.

5. Hirsch M, Carli P, Nizard R, Riou B, Baroudjian B, Baubet T, et al. The medical response to multisite terrorist attacks in Paris. Lancet Lond Engl. 2015 Dec 19;386(10012):2535-8.

6. Russo RM, Galante JM, Jacoby RC, Shatz DV. Mass casualty disasters: who should run the show? J Emerg Med. 2015 Jun;48(6):685-92.

7. Landman A, Teich JM, Pruitt P, Moore SE, Theriault J, Dorisca E, et al. The Boston Marathon Bombings Mass Casualty Incident: One Emergency Department's Information Systems Challenges and Opportunities. Ann Emerg Med. 2015 Jul;66(1):51-9.

8. Mclsaac JH. Hospital Preparation for Bioterror: A Medical and Biomedical Systems Approach. 3rd ed. Academic Press Elsevier; 2010. 462 p.

9. De Lorenzo RA. Financing hospital disaster preparedness. Prehospital Disaster Med. 2007 Oct;22(5):436-9.

10. Barbera JA, Yeatts DJ, Macintyre AG. Challenge of Hospital Emergency Preparedness: Analysis and Recommendations. Disaster Med Public Health Prep. 2009 Giugno;3(Supplement S1):S74-S82.

11. Domres B, Schauwecker HH, Rohrmann K, Roller G, Maier GW, Manger A. The German approach to emergency/disaster management. Med Arh. 2000;54(4):201-3.

12. Wyss K, Lorenz N. Decentralization and central and regional coordination of health services: the case of Switzerland. Int J Health Plann Manage. 2000 Jun;15(2):103-14.

13. Osterwalder JJ. Emergency medicine in Switzerland. Ann Emerg Med. 1998 Aug;32(2):243-7.

14. Federal Office of Public Health FOPH. Swiss Influenza Pandemic Plan [Internet]. 2016 [cited 2017 Nov 8]. Available from:

https://www.bag.admin.ch/bag/en/home/service/publikationen/broschueren/publikationenuebertragbare-krankheiten/pandemieplan-2016.html

15. RS 520.17 Ordinance of 20 October 2010 on the organization of intervention in case of NBC and natural disaster events (Ordinance on interventions NBCN) [Internet]. [cited 2017 Oct 26]. Available from: https://www.admin.ch/opc/it/classified-compilation/20090306/index.html

16. GDP per capita (current US\$) | Data [Internet]. [cited 2017 Nov 8]. Available from: https://data.worldbank.org/indicator/NY.GDP.PCAP.CD

17. Petinaux B. Financial burden of emergency preparedness on an urban, academic hospital. Prehospital Disaster Med. 2009 Oct;24(5):372-5.

18. Mahdaviazad H, Abdolahifar GR. Assessing hospital disaster preparedness in Shiraz, Iran 2011: teaching versus private hospitals. Am J Disaster Med. 2013;8(1):65-73. 
19. Dami F, Yersin B, Hirzel AH, Hugli O. Hospital disaster preparedness in Switzerland. Swiss Med Wkly. 2014;144:w14032.

20. Djalali A, Della Corte F, Foletti M, Ragazzoni L, Ripoll Gallardo A, Lupescu O, et al. Art of Disaster Preparedness in European Union: a Survey on the Health Systems. PLoS Currents [Internet]. 2014 Dec 17 [cited 2017 Sep 21]; Available from: http://www.ncbi.nlm.nih.gov/pmc/articles/PMC4323414/

21. Federal Office for Civil protection. The national risk analysis of Disaster and Emergencies in Switzerland. 2015 [cited 2017 Nov 8]; Available from:

http://www.babs.admin.ch/it/aufgabenbabs/gefaehrdrisiken/natgefaehrdanalyse.html

22. Koenig KL, Boatright CJ, Hancock JA, Denny FJ, Teeter DS, Kahn CA, et al. Health care facility-based decontamination of victims exposed to chemical, biological, and radiological materials. Am J Emerg Med. 2008 Jan;26(1):71-80.

23. Auf der Heide E. The Importance of Evidence-Based Disaster Planning. Ann Emerg Med. 2006 Jan;47(1):34-49.

24. Niska RW, Shimizu IM. Hospital preparedness for emergency response: United States, 2008. Natl Health Stat Rep. 2011 Mar 24;(37):1-14.

25. Powers R. Evidence-based ED Disaster Planning. J Emerg Nurs. 2009 May;35(3):218-23.

26. Noto R, Huguenard P, Larcan A. Médecine de catastrophe. second. Paris: Masson; 1994.

27. Belsky JB, Klausner HA, Karson J, Dunne RB. Survey of Emergency Department Chemical Hazard Preparedness in Michigan, USA: A Seven Year Comparison. Prehospital Disaster Med. 2016 Apr;31(2):224-7.

28. Mace SE, Bern AI. Needs assessment: are Disaster Medical Assistance Teams up for the challenge of a pediatric disaster? Am J Emerg Med. 2007 Sep;25(7):762-9.

29. Burke S, Bethel JW, Britt AF. Assessing Disaster Preparedness among Latino Migrant and Seasonal Farmworkers in Eastern North Carolina. Int J Environ Res Public Health. 2012 Aug 30;9(9):3115-33.

30. United Nations, Departement of Economics and Social Affairs. World Population Prospects: the 2017 revision [Internet]. [cited 2017 Sep 27]. Available from: https://esa.un.org/unpd/wpp/DataQuery/

31. IOM (Institute of Medicine). Preparedness, response, and recovery considerations for children and families: Workshop summary. Washington, DC: The National Academies Press. 2014.

32. Schultz Carl, Stratton Samuel. Improving Hospital Surge Capacity: A New Concept for Emergency Credentialing of Volunteers. Ann Emerg Med. 2007 May 1;49(5):602-9.

33. Fischer P, Wafaisade A, Neugebauer E a. M, Kees T, Bail H, Weber O, et al. Wie gut sind Ärzte auf einen Massenanfall von Verletzten vorbereitet? Unfallchirurg. 2013 Jan 1;116(1):34-8.

34. Powers R. Organization of a hospital-based victim decontamination plan using the incident command structure. Disaster Manag Response DMR Off Publ Emerg Nurses Assoc. 2007 Dec;5(4):119-23.

35. Hans Guggisberg, Thomas Herren. Istruzione degli organi cantonali di condotta: Un successo che continua. Prot Della Pop Riv Anal Dei Rischi E Prev Pianif E Istruzione Condotta E Interv. 2015 Jul $22 ; 20-1$. 


\begin{tabular}{|c|c|c|c|c|}
\hline Year & \multicolumn{2}{|l|}{2006} & \multicolumn{2}{|l|}{2016} \\
\hline Eligible EDs & \multicolumn{2}{|l|}{138} & \multicolumn{2}{|l|}{107} \\
\hline Response rate, $\mathrm{n}(\%)$ & \multicolumn{2}{|l|}{$108(78)$} & \multicolumn{2}{|c|}{$\mathrm{P}=(1.000)$} \\
\hline Characteristics & Total answers & $\begin{array}{l}\text { Have a plan } \\
\text { for massive } \\
\text { patient inflow }\end{array}$ & Total answers & $\begin{array}{l}\text { Have a plan } \\
\text { for massive } \\
\text { patient inflow }\end{array}$ \\
\hline EDs response, $\mathbf{n}(\%)$ & 108 & $89(82)$ & 83 & $\begin{array}{l}76(92) \\
P=0.088\end{array}$ \\
\hline Public vs. Private hospital & 108 & $P=0.017$ & 83 & $P=0.107$ \\
\hline Private hospital & $14(13)$ & $8(57)$ & $15(18)$ & $12(80)$ \\
\hline Public hospital & $94(87)$ & $81(86)$ & $68(82)$ & $64(94)$ \\
\hline $\begin{array}{l}\text { Number of acute hospital beds } \\
\text { (\%) }\end{array}$ & 108 & $P=0.228$ & 83 & $P=0.946$ \\
\hline$<100$ & $35(32)$ & $25(71)$ & $26(31)$ & $24(92)$ \\
\hline $100-199$ & $42(39)$ & $36(86)$ & $31(37)$ & $28(90)$ \\
\hline $200-499$ & $23(21)$ & $20(87)$ & $17(21)$ & $15(88)$ \\
\hline$\geq 500$ & $7(8)$ & $7(100)$ & $9(11)$ & $9(100)$ \\
\hline $\begin{array}{l}\text { Hospital with intensive care unit, } \\
\text { n (\%) }\end{array}$ & $64(63)$ & $55(86)$ & $59(71)$ & $\begin{array}{l}54(92) \\
P=(1.000)\end{array}$ \\
\hline Linguistic regions & 108 & $P=0.550$ & 83 & $P=0.040$ \\
\hline German part & $71(66)$ & $57(80)$ & $60(72)$ & $57(95)$ \\
\hline French part & $29(27)$ & $24(83)$ & $16(19)$ & $12(75)$ \\
\hline Italian part & $8(7)$ & $8(100)$ & $7(9)$ & $7(100)$ \\
\hline $\begin{array}{l}\text { University vs. non-University } \\
\text { hospital }\end{array}$ & 108 & $P=0.210$ & 82 & $P=1.000$ \\
\hline University hospital & $11(100)$ & $11(100)$ & $7(100)$ & $7(100)$ \\
\hline Non university hospital & $97(90)$ & $78(80)$ & $75(91)$ & $69(91)$ \\
\hline
\end{tabular}


Table 2: Features of disaster plans in 2016

\begin{tabular}{|c|c|c|c|c|}
\hline Type of disaster $\mathbf{n}(\%)$ & $\mathrm{N}=83$ & Plan activated & \multicolumn{2}{|c|}{$\mathrm{N}=80$} \\
\hline Mass influx of patients (major accident) & $76(92)$ & \multirow{2}{*}{ Plan activated in last 3 years } & \multirow{2}{*}{\multicolumn{2}{|c|}{ Average: 0.53}} \\
\hline Hospital accident (fire, black-out, & $76(92)$ & & & \\
\hline security or communication problem) & & \multirow[t]{2}{*}{ Plan tested in last 3 years } & \multirow{2}{*}{\multicolumn{2}{|c|}{$N=80$}} \\
\hline Infectious problem (e.g.: Ebola, SARS) & $65(79)$ & & & \\
\hline NRBC+B+T risks & $\mathrm{N}=80$ & HICS activation only & \multicolumn{2}{|l|}{$38(48)$} \\
\hline Nuclear/radiologic & $14(18)$ & Simulated patients & \multicolumn{2}{|l|}{$33(41)$} \\
\hline Biological & $\frac{25(31)}{27(34)}$ & Descriptive cards & \multicolumn{2}{|c|}{$27(34)$} \\
\hline Chemical & $\frac{27(34)}{15(19)}$ & Plan tested $\geq 1$ time /year & \multicolumn{2}{|c|}{ Yes $42(52)$} \\
\hline$\frac{\text { Burned }}{\text { Polytraumatised }}$ & $\frac{15(19)}{46(58)}$ & Plan tested $\geq 1$ time $/ 3$ years & \multirow{2}{*}{\multicolumn{2}{|c|}{ Yes $80(100)$}} \\
\hline Plan designed for specific & $\begin{array}{l}46(58) \\
N=80\end{array}$ & & & \\
\hline populations of patients & $10-6$ & Presence of a HICS & \multicolumn{2}{|l|}{$\mathrm{N}=80$} \\
\hline Children & $19(24)$ & HICS present & \multicolumn{2}{|l|}{$70(88)$} \\
\hline Geriatric patients & $12(15)$ & Leader of HICS & \multicolumn{2}{|l|}{$\mathrm{N}=68$} \\
\hline Migrants & $10(13)$ & Hospital's board member & \multicolumn{2}{|l|}{$38(56)$} \\
\hline Reception of Relatives & $33(41)$ & ED medical officer & \multicolumn{2}{|l|}{$14(21)$} \\
\hline In charge of the victims' relatives & $\mathrm{N}=80$ & Surgery medical officer & \multicolumn{2}{|l|}{$4(6)$} \\
\hline Staff from Emergency department & $37(46)$ & \multirow{2}{*}{ Anaesthesia medical officer } & \multirow{2}{*}{\multicolumn{2}{|c|}{$1(2)$}} \\
\hline Staff from Psychiatry department & $11(14)$ & & & \\
\hline Staff from other departments & $31(39)$ & \multirow{2}{*}{$\begin{array}{l}\text { Specialist according to the type of } \\
\text { accident }\end{array}$} & \multirow{2}{*}{\multicolumn{2}{|c|}{$3(5)$}} \\
\hline Other & $30(38)$ & & & \\
\hline Patients' flow management & $\mathrm{N}=80$ & Other & \multicolumn{2}{|l|}{$8(11)$} \\
\hline $\begin{array}{l}\text { The flow of daily patients is separate } \\
\text { from the disaster's flow }\end{array}$ & Yes $41(51)$ & $\begin{array}{l}\text { Time needed for HICS to be } \\
\text { operational }\end{array}$ & $N=68$ & \\
\hline $\begin{array}{l}\text { Type of support used for managing } \\
\text { patient's flow in a Daily situation }\end{array}$ & $\mathrm{N}=83$ & $<20$ minutes & $7(10)$ & \\
\hline Digital support & $67(81)$ & $20-40$ minutes & $38(56)$ & \\
\hline Paper & $20(24)$ & $>40 \quad$ minutes & $23(34)$ & \\
\hline Other & $3(4)$ & Type of risk treated & $\mathrm{N}=78$ & \\
\hline None & $4(5)$ & Chemical & $47(60)$ & \\
\hline Type of support used for managing & $\mathrm{N}=78$ & Biological & $32(41)$ & \\
\hline patient's flow in a Disaster situation & & Nuclear/radiologic & $25(32)$ & \\
\hline Digital support & $52(67)$ & No decontamination zone & $30(39)$ & \\
\hline Paper & $56(72)$ & Readiness of decontamination & $\mathrm{N}=48$ & \\
\hline Other & $6(8)$ & zone & & \\
\hline None & $5(6)$ & Time necessary to be operational & Average & Median \\
\hline Hospital access control manager & $\mathrm{N}=80$ & $(\min )$ & 40.3 & \\
\hline Private security & $29(36)$ & Decontamination manager & $\mathrm{N}=48$ & \\
\hline Police & $24(30)$ & & & \\
\hline Other (technical staff) & $34(43)$ & Hospital care staff & $26(54)$ & \\
\hline None & $13(16)$ & Hospital Technical staff & $23(48)$ & \\
\hline Recall of Additional staff & $\mathrm{N}=80$ & Professional firefighters & $19(40)$ & \\
\hline ED's staff & $74(93)$ & Civil protection (FEMA in USA) & $1(2)$ & \\
\hline Staff from other departments & $71(89)$ & & & \\
\hline Administrative staff & $64(80)$ & Army (NBC troops) & $1(2)$ & \\
\hline None & $1(2)$ & Other & $10(21)$ & \\
\hline Information regarding the plan $\mathbf{n}(\%)$ & $N=78$ & Protection equipment & $\mathrm{N}=48$ & \\
\hline $\begin{array}{l}\text { Periodic instruction } \\
\text { Hospital web page }\end{array}$ & $\begin{array}{l}50(64) \\
49(63)\end{array}$ & 3M mask and disposable gloves & $44(92)$ & \\
\hline Training/simulations & $23(29)$ & & & \\
\hline Word of mouth & $15(19)$ & Light chemical protective seal (PPE) & $38(79)$ & \\
\hline Pocket card & $11(14)$ & & & \\
\hline Internal paper mail & $7(9)$ & Other & $7(15)$ & \\
\hline None & $8(10)$ & None & $2(4)$ & \\
\hline
\end{tabular}



Figure 1: Awareness of the plan

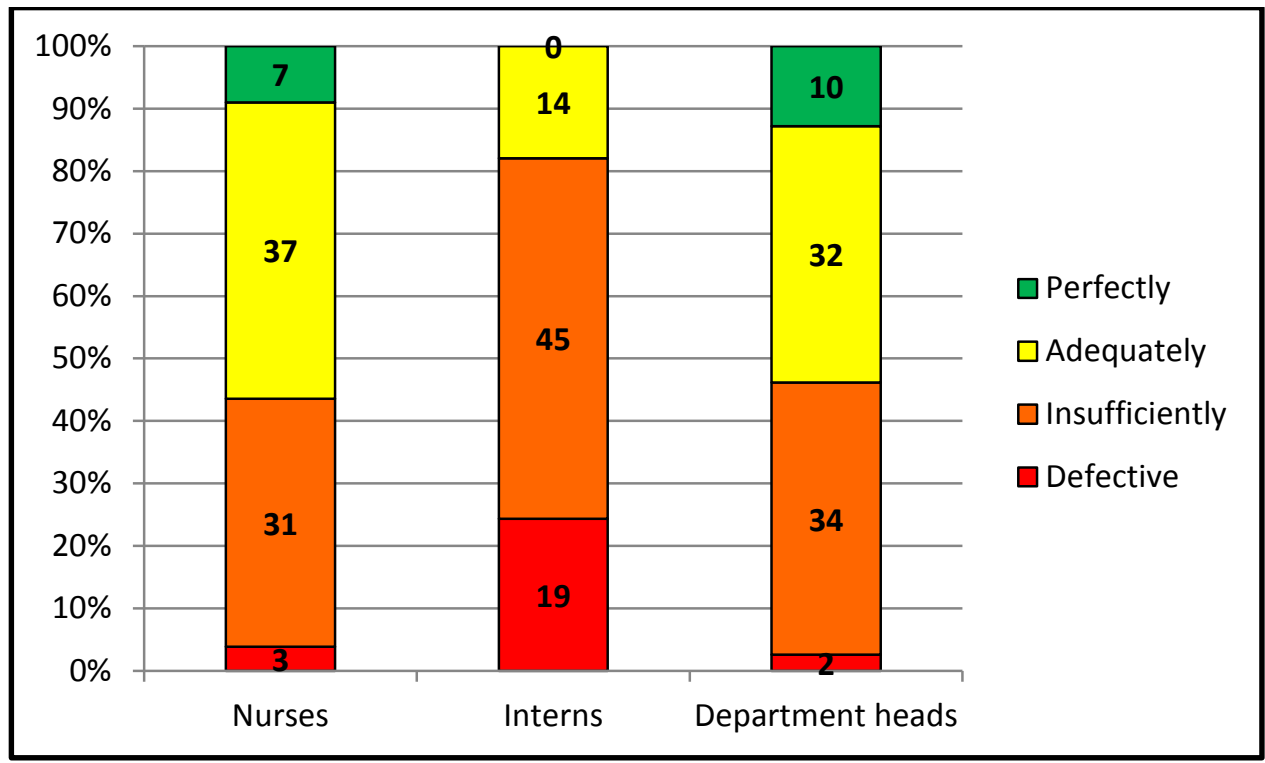




\begin{tabular}{|c|c|}
\hline \multicolumn{2}{|c|}{$\begin{array}{l}\text { Annexe } 1 \text { Collaborations to elaborate the } \\
\text { plan } N=80(\%)\end{array}$} \\
\hline State & $46(58)$ \\
\hline EMS & $43(54)$ \\
\hline Firefighters & $33(41)$ \\
\hline Nearby hospitals & $29(36)$ \\
\hline Police & $23(29)$ \\
\hline Country (Swiss) & $13(16)$ \\
\hline Army & $5(6)$ \\
\hline Civil Protection & $3(4)$ \\
\hline None & $14(18)$ \\
\hline
\end{tabular}

Annexe 1 Collaborations to elaborate the

plan $N=80(\%)$ 


\begin{tabular}{|l|l|}
\hline $\begin{array}{l}\text { Annexe } 2 \text { Declared incentives for disaster } \\
\text { plan's development: } \mathbf{N}=\mathbf{8 0}(\%)\end{array}$ \\
\hline Hospital requirement & $45(56)$ \\
\hline State's requirement & $39(49)$ \\
\hline Individual initiative within hospital & $30(38)$ \\
\hline Future major event in the region & $19(24)$ \\
\hline National requirement & $6(8)$ \\
\hline National financial support & $0(0)$ \\
\hline State's financial support & $0(0)$ \\
\hline Other & $10(13)$ \\
\hline None & $3(4)$ \\
\hline
\end{tabular}

